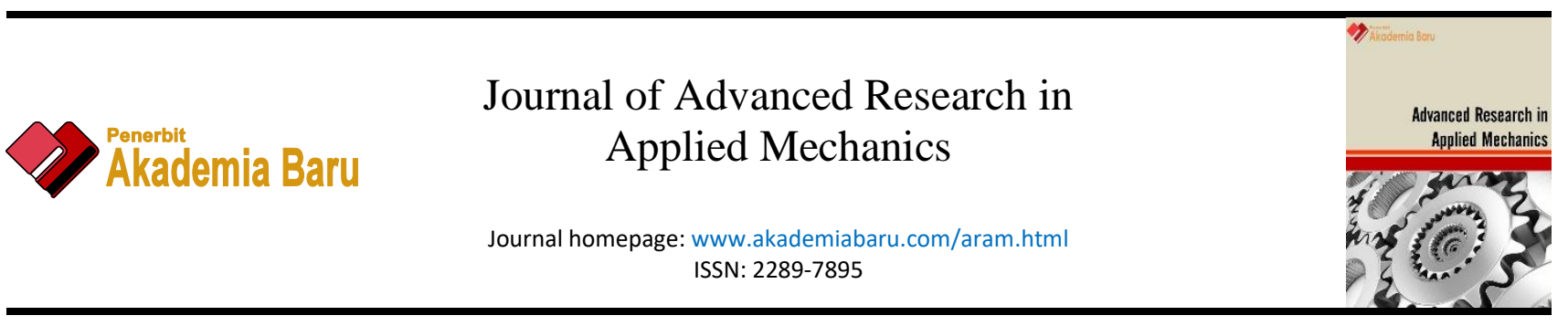

\title{
Experimental Study On Waste Heat Recovery from an Internal Combustion Engine Using Thermoelectric Generator
}

\author{
Nor Amelia Shafikah Mat Noh ${ }^{1}$, Baljit Singh Bhathal Singh ${ }^{1,}{ }^{*}$, Muhammad Fairuz Remeli ${ }^{1}$, \\ Amandeep Oberoi ${ }^{2}$
}

Fakulti Kejuruteraan Mekanikal, Universiti Teknologi MARA, 40450 Sha Alam, Selangor, Malaysia

Department of Mechanical Engineering, Thapar Institute of Engineering and Technology, Patiala, India

\section{ABSTRACT}

An internal combustion engine (IC engine) is a heat engine that the combustion of fuel takes place that particular interest in transportation. A major part of heat supplied from the IC engine not recognized into work output but expelled into the environment as waste heat. The waste heat can be tapped and convert it into useful energy that can increase the performance of the system. The project focus on the utilization of the waste heat range temperature of the IC engine by using the device thermoelectric generator (TEG). TEG is a solid device that can directly convert waste heat into electrical energy as the temperature difference present in the system. The aim of the project to optimize the power generation in an array configuration of the TEG electrical connection. Two TEG had the individual test to attain the electrical characterization and also test on series and parallel connection that theoretically the series connection generated high voltage compare to parallel TEG. The variable that is considered in this experiment is heat source temperature that performs the electrical output, voltage, and current. The study shows that the series connection of TEG had improved and increased in voltage generated but parallel connection more reliable. Overall conclusion, the series connection successfully generated the highest maximum output power from IC engine waste heat but more study on improvement of the heat exchanger to increase the airflow and temperature difference of TEG is required.

\section{Keywords:}

thermoelectric generator; waste heat recovery; internal combustion engine; efficiency

Copyright @ 2020 PENERBIT AKADEMIA BARU - All rights reserved

\section{Introduction}

An internal combustion engine (IC engine) is a heat engine in which the combustion of a fuel occurs. In the combustion chamber the fuel mixing with air that produces the working fluid. The force that applied in the combustion channel will transform the chemical energy into mechanical work. An analysis of the European Commission showed that the percentage of greenhouse gases in the atmosphere is composed of carbon dioxide is about $80 \% .25 \%$ parts of the carbon dioxide expose to the atmosphere is produced by transport which causes the burning of fossil fuels in an internal combustion engine [1]. In the internal combustion engine system, the effective conventional is nearly about $30-35 \%$ while the rest is expelled through waste heat dissipation into the atmosphere and lost

\footnotetext{
* Corresponding author.

E-mail address: baljit@uitm.edu.my
}

https://doi.org/10.37934/aram.72.1.2536 
as engine cooling. In order to minimize the energy losses by recovering the waste heat in the internal combustion engine. It also will maximize the efficiency of the overall performance of the IC engine. It would possible to reduce fuel consumption by around 10\% [2]. A waste heat source that can be recovered in the engine is the energy released in the coolant system and exhaust gas. The heat rejected through the exhaust is in high temperature compare with heat loss through the engine coolant. It shows the possibility of the waste heat recovery from exhaust heat by using a thermoelectric generator [3]. The average temperature of the exhaust system of car in a range of $300^{\circ} \mathrm{C}$ to $500^{\circ}$. However, the system can reach about $1200{ }^{\circ} \mathrm{C}$ of temperature when there is a constriction in the exhaust system [4]. Waste heat can be recovered through the method of capturing and transferring the waste heat from a process with a gas or liquid back to the system as an extra energy source. The energy source that created can be used or generated electrical or mechanical power. The heat generated in the IC engine can be categorized as a high temperature that the temperature above $400{ }^{\circ} \mathrm{C}$. The higher the temperature range, the higher the quality of the waste heat and easier optimization of the waste heat recovery process [5].

Thus, the thermoelectric generator (TEG) is a solid device that recovered the waste heat from the IC engine to electrical power. It will convert directly thermal energy into electrical energy. The thermoelectric generator also operates quietly and does not has a moving part as it a solid device [6]. The operating principle of TEG based on the Seebeck whereby the generated electricity based on the temperature gradient between the hot and cold side of TEG. The temperature differential from the hot and cold source is applied across the face of modules of TEG that possible to produce the voltage. Thermoelectric generators that work on Seebeck effect that have efficiencies around 5-10\% [7].

A heat exchanger is usually defined as the device that allows the passing of heat from a fluid to the other fluid without mixing each other. The heat from the exhaust will transmit into the heat exchanger. The shape and size of the heat exchanger will affect the distribution profile of heat velocity [8]. A higher the velocity of heat implies the higher coefficient of heat transfer due to the increasing speed of gas. The heat exchanger developed by the previous experiment improved the efficiency of the system. In this test that also focusing on enhancing the performance of the TEG from the previous experiment in different array TEG configuration. The project conducted is an experiment to compare the power output due to the different electrical connections of the thermoelectric generator.

\section{Methodology}

The objectives of this project are to determine the maximum power of the thermoelectric generator in $\mathrm{IC}$ engine applications and to evaluate the performance of the thermoelectric generator in different electrical connections. In order to achieve the objectives above, the suitable test bench had was developed to improve the speed of the airflow. The flow of the project divided into two major parts which are the development of heat exchanger and installation setup of the experiment.

\subsection{Development of Heat Exchanger}

A heat exchanger (HEX) is a main part of the test section in this experiment that transfers heat from heat source. In this experiment, the new development of heat exchanger as the improvement from the previous project to improve the maximum power extracted from TEG that contact with a hot surface. The concept of the heat exchanger is to increase the speed of hot airflow along the transition from the inlet to the outlet of the heat exchanger to avoid fluid spread to the surrounding. The improvement of the heat exchanger design considering a proper hot airflow channel to receive 
from the heat source. The previous design had maintained and the reducer had added to the inlet channel as the size same with the heat gun nozzle. Therefore it can reduce the airflow from losses to the surrounding. The aluminum rod had applied at the inlet channel as the reducer to collect the heat air source in various temperatures. The diameter of the steel rod suite with heat gun nozzle in short length to increase the average heat transfer coefficient. The surface of the heat exchanger and reducer had covered with a heat insulator to prevent the heat from escaping at the wall. The parameters of the heat exchanger had shown in Table 2.

\section{Table 1}

Studied on waste heat recovery from the IC engine using TEG

\begin{tabular}{lll}
\hline Years & \multicolumn{1}{c}{ Waste Heat Recovery System } & \multicolumn{1}{c}{ Results } \\
\hline 2011 & $\begin{array}{l}\text { C. R. KUMAR et. al researched in waste heat recovery using 9 TEG that } \\
\text { electrically connected in a series IC system. The heat source from the } \\
\text { exhaust system supplied and the coolant used in the engine cooling }\end{array}$ & $\begin{array}{l}\text { The highest power output } \\
\text { achieved was } 70 \mathrm{~W} \text { at } 120\end{array}$
\end{tabular}
system circulated in TEG [8].

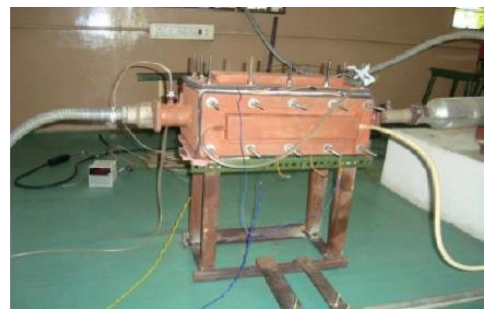

Fig. 1. Complete assemble of TEG

2012 N. D. Love et. al studied on exhaust heat recovery with five $\mathrm{Bi}_{2} \mathrm{Te}_{3}$ thermoelectric devices are placed in between the two stainless steel heat exchangers. The engine is operated at a speed of $1500 \mathrm{rpm}$ and $70 \%$ load that supplied waste heat in the exhaust pipe. The coolant used for a cooling method at a heat exchanger [9].

2014 The studied on heat recovery by AravindKaruppaiah.C et.al in exhaust system on design and analysis of TEG with the material used. Waste gas present in the IC engine as a hot temperature source and air cooling system contact with an aluminum fin that produces the temperature difference of TEG [10].

2015 In 2015, a research conducted by R. Mathai Chandy Rakesh Rajeev et. al on design and analysis of heat exchanger for automotive exhaust based on TEG. Two TEG provided in series that attached to two heat exchangers and the exhaust gas supplied the hot heat in the system. The automotive air condition evaporator side as the cooling method provided to the heat exchanger [11].

$2015 X$. Liu et. al conducted the studied on performance analysis of waste heat recovery in the automotive system by TEG. Exhaust pipe supplied heat source to four TEG that connected in parallel. The cooling water tanks as the cooling source for the system [12].
The higher temperature supplied in the exhaust was $280{ }^{\circ} \mathrm{C}$ and coolant temperature, $40{ }^{\circ} \mathrm{C}$ that resulted in $3.8 \mathrm{~W}$.

The exhaust temperature varies at $145^{\circ} \mathrm{C}$ until $175^{\circ} \mathrm{C}$ that resulted in $17.5 \mathrm{~V}$ of the maximum voltage.

The result obtains in $100{ }^{\circ} \mathrm{C}$ of temperature difference that produced $0.534 \mathrm{~V}$ of voltage.

The output power
obtained was $600 \mathrm{~W}$ in 182
${ }^{\circ} \mathrm{C}$ of temperature
difference.




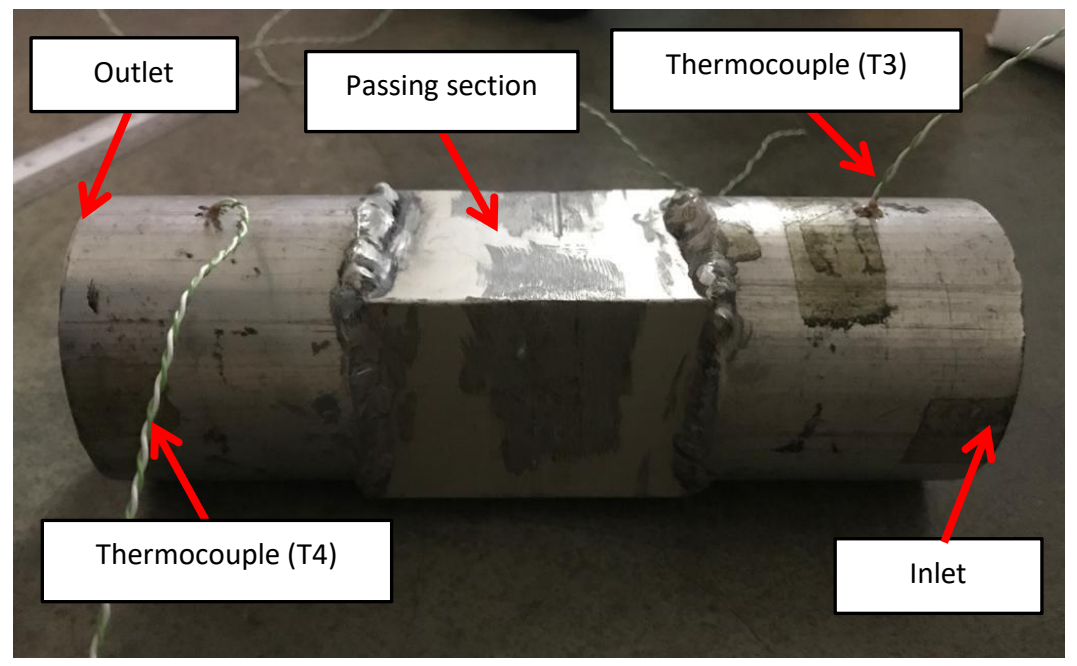

Fig. 2. Heat exchanger

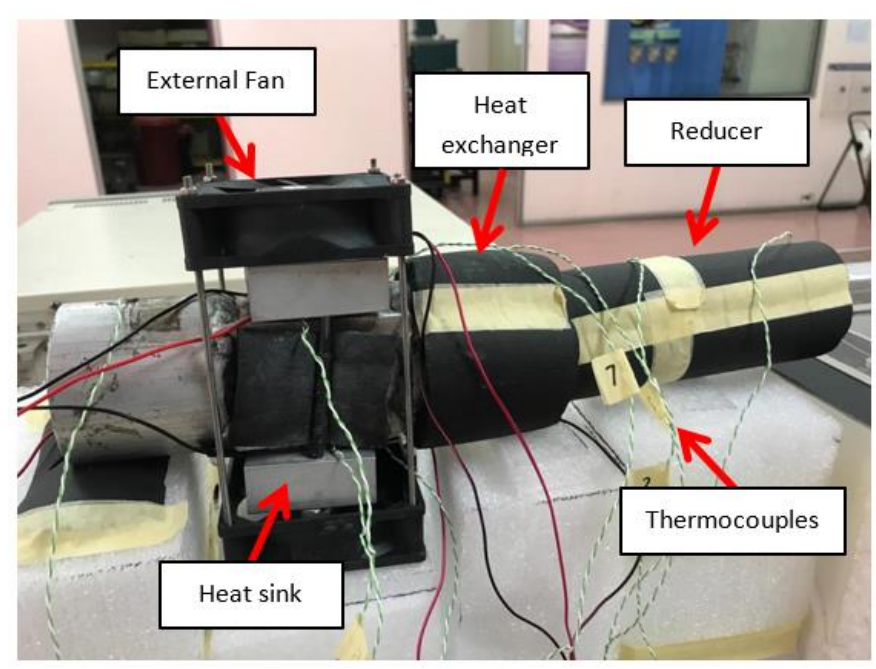

Fig. 3. Heat exchanger after insulated

Table 2

Parameters of heat exchanger and reducer

Parameter

\section{Heat Exchanger}

Thickness

Length

Diameter

Material

Melting Point

Flexibility

Durability

Strength

\section{Reducer}

Thickness

Length

Diameter

Material
Value

$165 \mathrm{~mm}$

$2.5 \mathrm{~mm}$

$60 \mathrm{~mm}$

Aluminum

$660{ }^{\circ} \mathrm{C}$

High

High

high

$5 \mathrm{~mm}$

$200 \mathrm{~mm}$

$38.5 \mathrm{~mm}$

Aluminum 


\subsection{Installation and Setup}

A test bench had set up to experiment with obtaining the objectives to evaluate the power output from TEG of recovering waste heat engine. The system had shown in the schematic diagram that can be referred to in Figure 4. The hot source supplied was a heat gun as the operation of a heat gun was interrelated with the actual performance of the exhaust engine for the experiment. The heat exchanger and reducer were insulated with a thermal insulator to minimize the heat loss. There were nine type-k thermocouple wires had connected to the midi LOGGER GL220A. The thermocouples wires had been connected to gain the reading of the temperature at the exact points. Besides, two thermoelectric generators had tested in this experiment that connected to electronic load for gaining the output voltage and current reading produced by TEG. The $12 \mathrm{~V}$ external fan as forced convection on the cold side of TEG as a cooling method that attached to the heat sink. Two external fans had sourced from the power supply. The condition on the cold side of TEG with the external fan fix to the heat sink to achieve and maintain the temperature difference between the TEG.

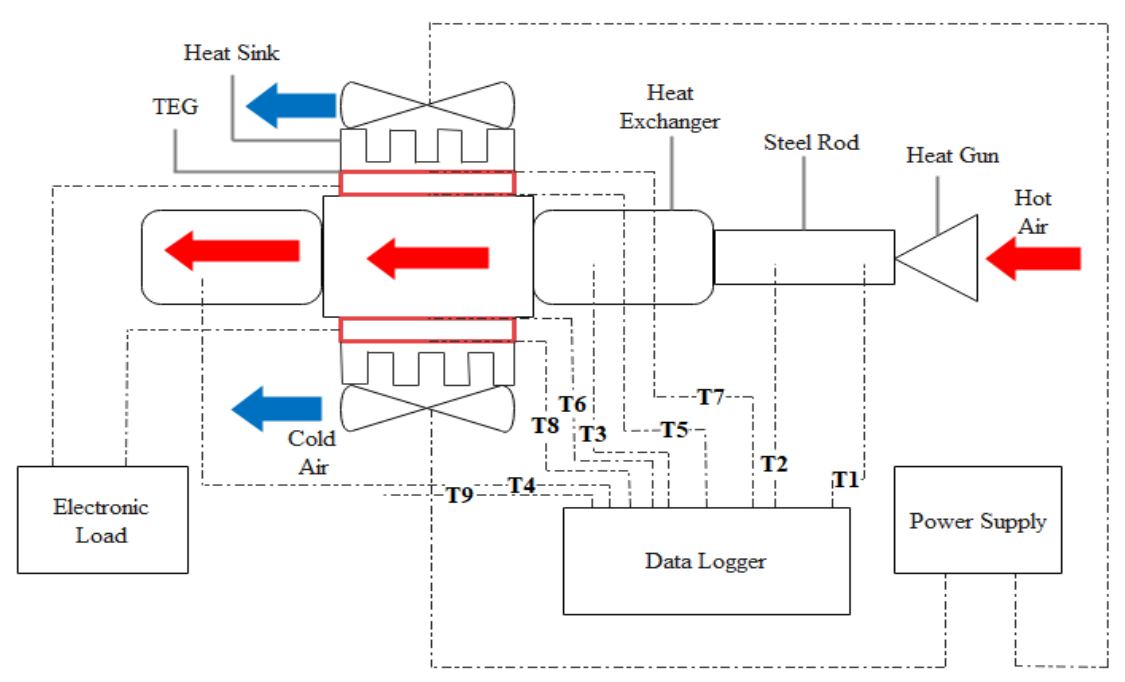

Fig. 4. Schematic diagram of the experimental setup

The connection of individual TEG, TEG 1, and TEG 2 had tested in four different waste heat source temperatures to identify the electrical characterization of each TEG. Waste heat sources were varied by changing the temperature of the heat gun. In addition, two TEG also had a test in series and parallel of electrical connection. The purpose in the testing of different modes of connection to recognize the difference of electrical characterization with combination TEG array configuration.

\section{Results}

In order to observe the differential change in electrical characterizations due to the addition of TEG to the exhaust system, experiments were conducted on the test bench with individual TEG, series and parallel connection TEG and the results were compared. In the test, the heat source temperature of the system had supplied in a different value, $100^{\circ} \mathrm{C}, 150^{\circ} \mathrm{C}, 200^{\circ} \mathrm{C}$ and $250^{\circ} \mathrm{C}$, while the heat sink temperature was kept unchanged with $11.6 \mathrm{~V}$ of the external fan. The value of load $\mathrm{R}_{\mathrm{L}}$ was adjusted from $10 \Omega$ to $0.25 \Omega$, at the same time, the output voltage and current of the TEG system were carefully measured. 


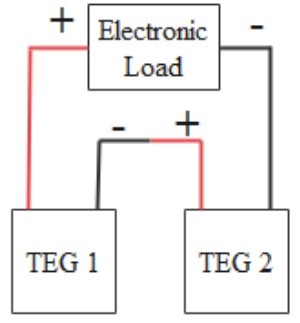

Series

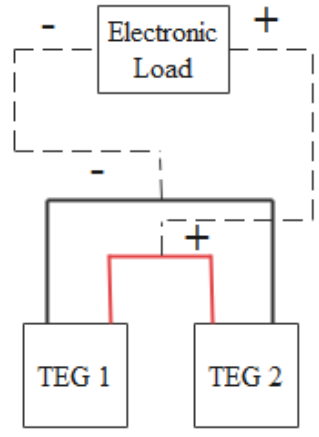

Parallel

Fig. 5. Schematic diagram of TEG connections

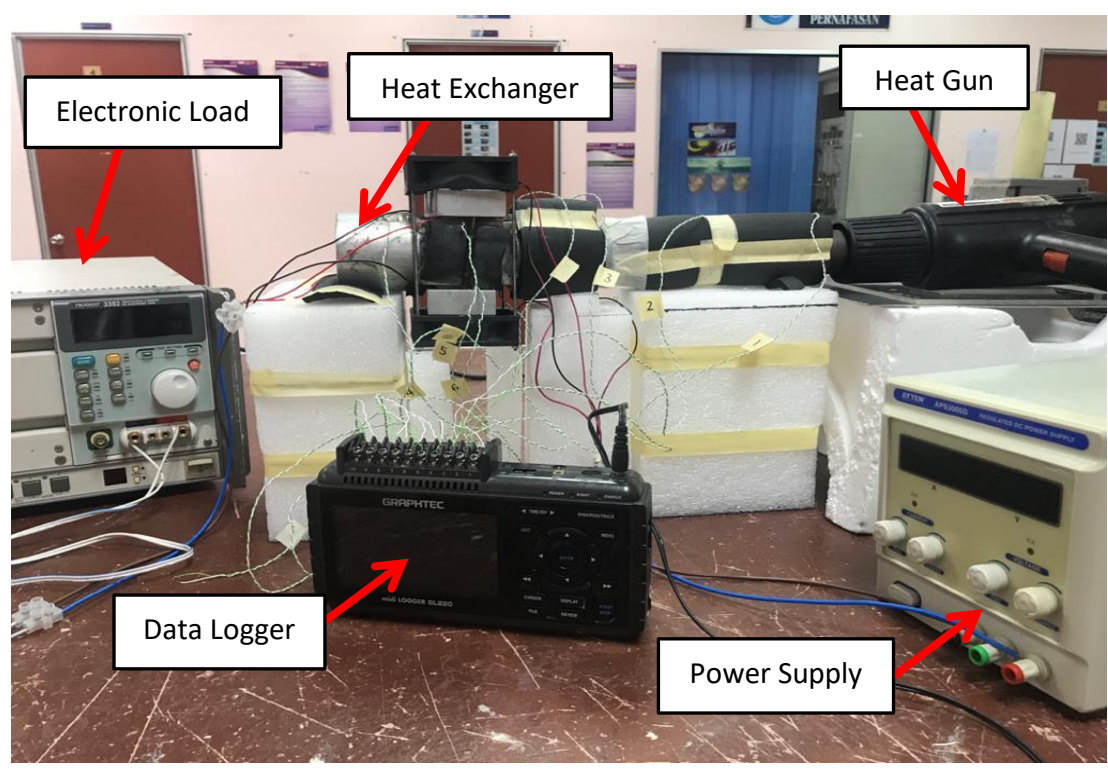

Fig. 5. Experimental setup

\subsection{Individual TEG}

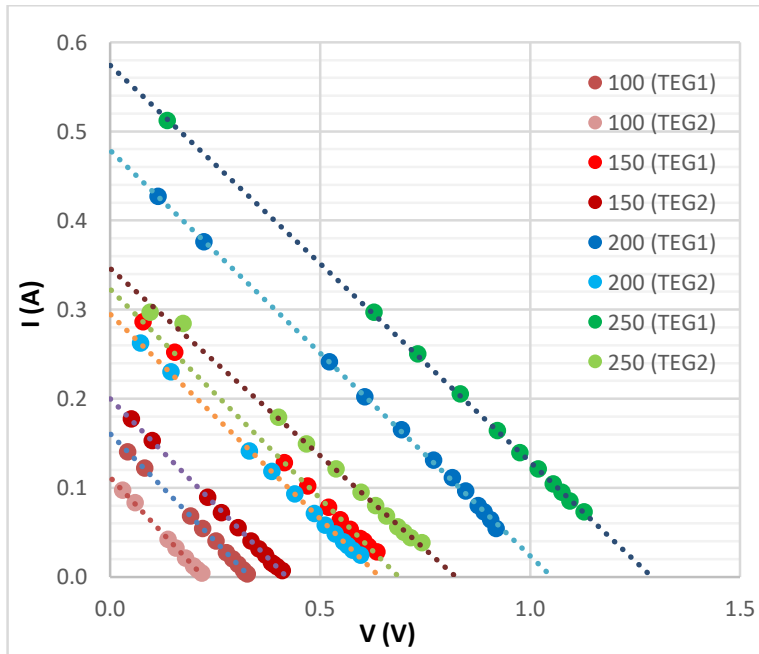

Fig. 6. Current profile of TEG 1 and TEG 2

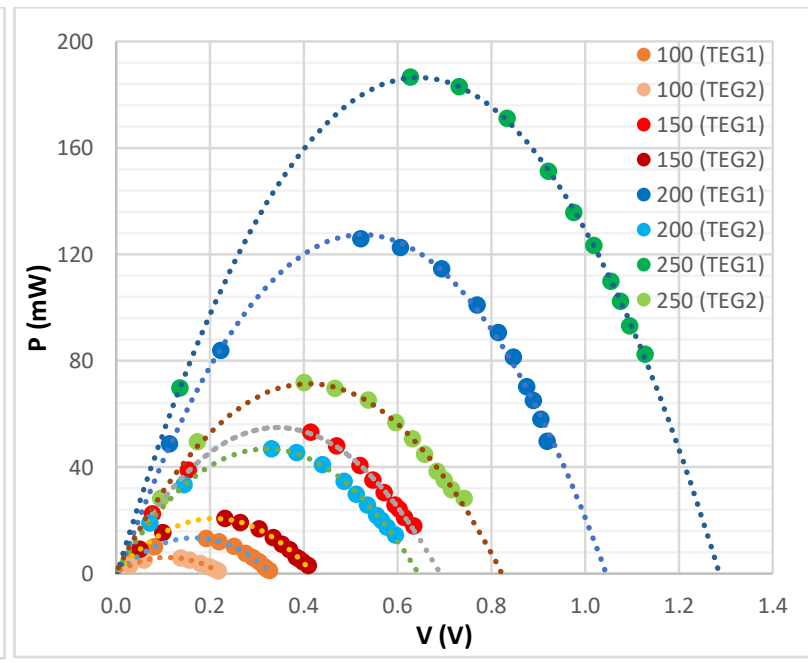

Fig. 7. Power output profile of TEG 1 and TEG 2 
Figure 7 and Figure 8 show the comparison results of output current and power of TEG 1, TEG 2 with respect to the output voltage. The current fell consistently as the voltage increase in the system. TEG 1 achieved the maximum output current with $0.58 \mathrm{~A}$ while for TEG 2 it reached $0.342 \mathrm{~A}$ at 250 ${ }^{\circ} \mathrm{C}$, waste heat source temperature. After that, as illustrated in Figure 8 , the output power increase as the output voltage increase. The value of output power increased until it reached the maximum power point then it started to decrease that performed the curve profile graph. The output voltage had generated based on the temperature gradient that also produced the current in the circuit. The output power had obtained and calculated based on formula P=IV. For TEG 1, the temperature of $250{ }^{\circ} \mathrm{C}$ had achieved the highest maximum power with $183 \mathrm{~mW}$ compared to the other three various temperatures of waste heat. Then, TEG 2 obtained the highest maximum power at $250{ }^{\circ} \mathrm{C}$ with 17 $\mathrm{mW}$. It shows that TEG 1 had the best performance than TEG 2 due to the airflow of the heat source always going up that produced a larger output voltage that resulted in the maximum power. The curves showing the TEG maximum output power as a function of the temperature differential were plotted and the results are given respectively in Figure 9. The output power increases with an increase in a temperature difference $(\Delta T)$, this is due to an increase in waste heat source with an increase in power output. The highest maximum power of TEG 1 achieved at $32.6^{\circ} \mathrm{C}$ of temperature different meanwhile TEG 2 performed the highest value of MPP at $17.1^{\circ} \mathrm{C}$. It clearly shows that, the larger gap value between the TEG 1 and TEG 2 due to technical error in the experiment when the arrangement of test bench that blocked the cooling airflow that resulted in the output power of the system.

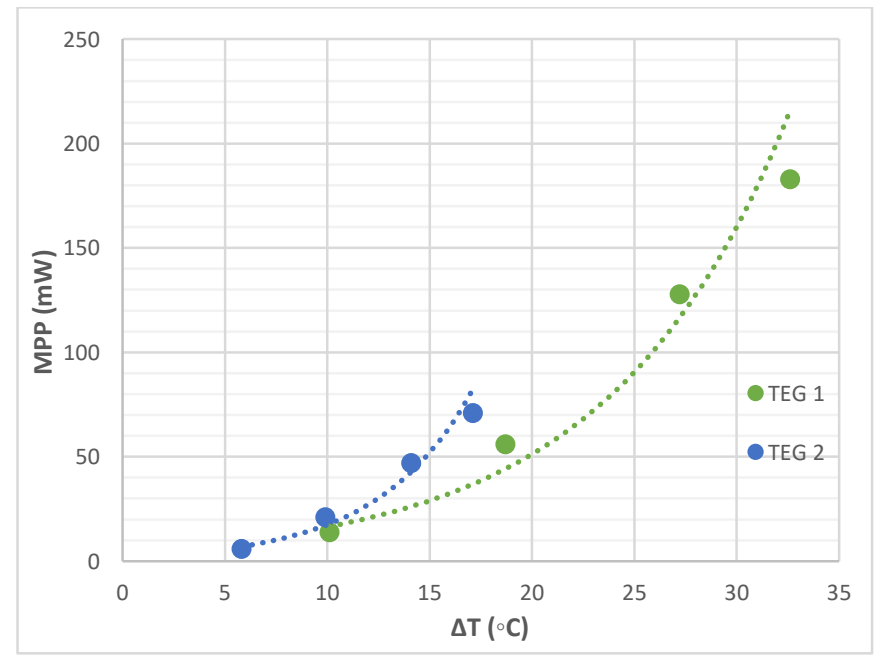

Fig. 8. Maximum power output at various temperature different of TEG 1 and TEG 2

The heat transition along the inlet to outlet of heat exchanger based on the distance also been measured as the result illustrated in Figure 10. For TEG 1 and TEG 2, the furthest distance point from heat source was $35 \mathrm{~cm}$ that received only $153.1{ }^{\circ} \mathrm{C}$ and $109.1{ }^{\circ} \mathrm{C}$ of the temperature at $250{ }^{\circ} \mathrm{C}$ waste heat source. The results show that the heat loss along with the distance of the transmission. The shortest distance from a heat source that recorded was $1.5 \mathrm{~cm}$ that received a lot amount of heat which $104.5^{\circ} \mathrm{C}$ and $115.9^{\circ} \mathrm{C}$ for TEG 1 and TEG 2 at $100^{\circ} \mathrm{C}$ heat source. Then, the distance of located TEG from the heat source was $20.75 \mathrm{~cm}$. The highest maximum temperature received by TEG was $80.1{ }^{\circ} \mathrm{C}$ at $250{ }^{\circ} \mathrm{C}$. It affected the temperature difference that resulted in voltage and power generated. 


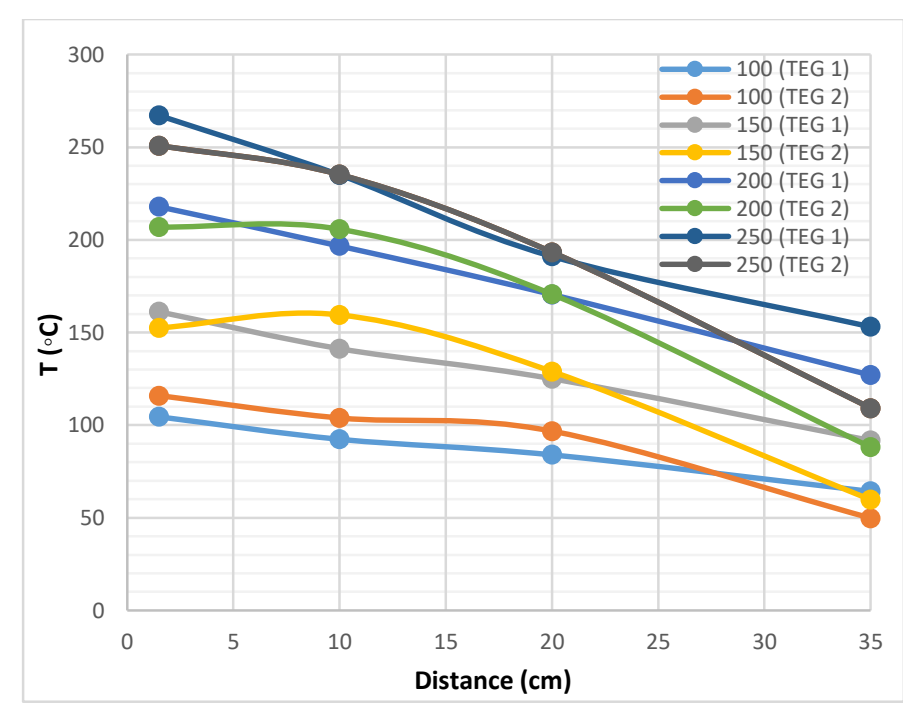

Fig. 9. Temperature along with the distance from heat source for TEG 1 and TEG 2

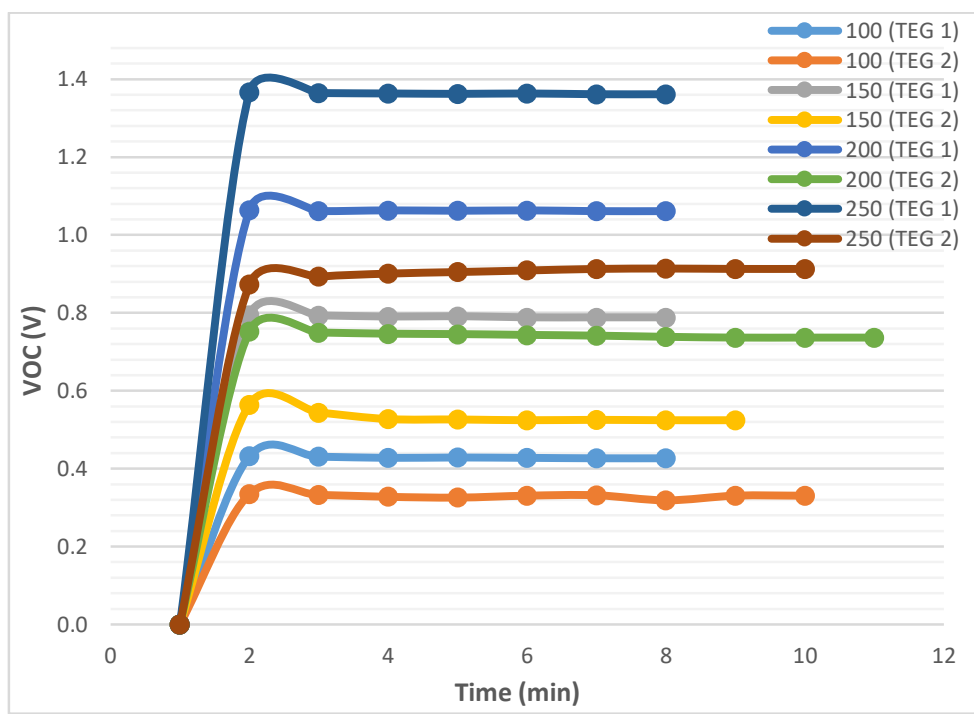

Fig. 10. Open circuit voltage against the time taken for TEG 1 and TEG 2

The time taken had recorded as for the voltage achieved the steady-state in the open circuit as shown in Figure 11. The voltage recorded in the open circuit stage as no-load applied in the system. The average time was taken for the voltage to achieve steadily for TEG 1 and TEG 2 around 8 minutes. The longest time take by TEG 2 at $200^{\circ} \mathrm{C}$ to achieve a steady part was 11 minutes.

\subsection{Series and Parallel TEG}

The comparison of series and parallel TEG can be referred to in Figure 12 and Figure 13 based on current and power extracted from the TEG connection. It clearly shows that the performance of multi- TEG better than one TEG in the system. Based on Figure 12, shows that the current decrease steadily as the output voltage increase. The maximum current obtained in series was $0.48 \mathrm{~A}$ while in parallel was $0.86 \mathrm{~A}$ at $250^{\circ} \mathrm{C}$ waste heat source. By comparing the results of series and parallel TEG, the electrical characteristics generated in the series were relatively in large voltage with a small current that leads to the electrical efficiency of the system. Moreover, as the value of the current lower, the resistance losses also lower which resulted in the small energy loss in the system. 
Therefore, the efficiency of the system will increase. Apart from that, the current produced by TEG in parallel array connection was higher with less value of voltage.

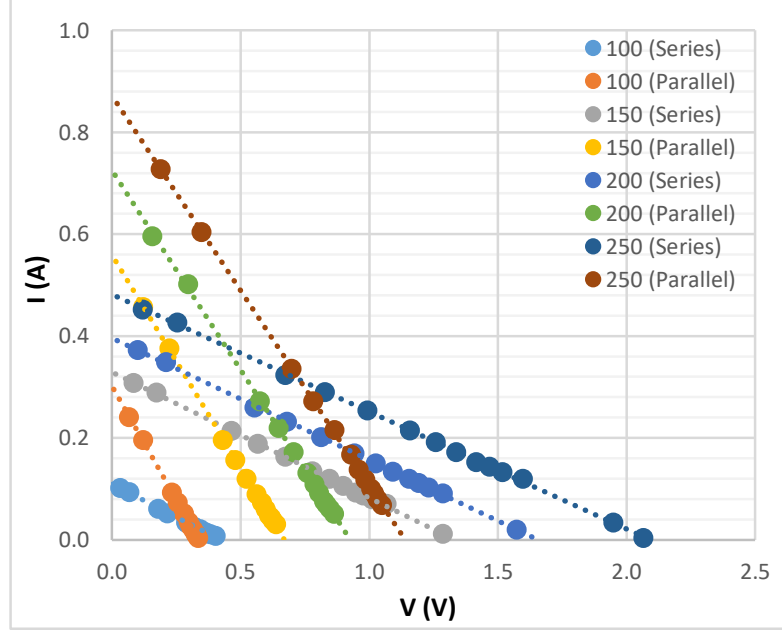

Fig. 11. Current profile of series and parallel TEG

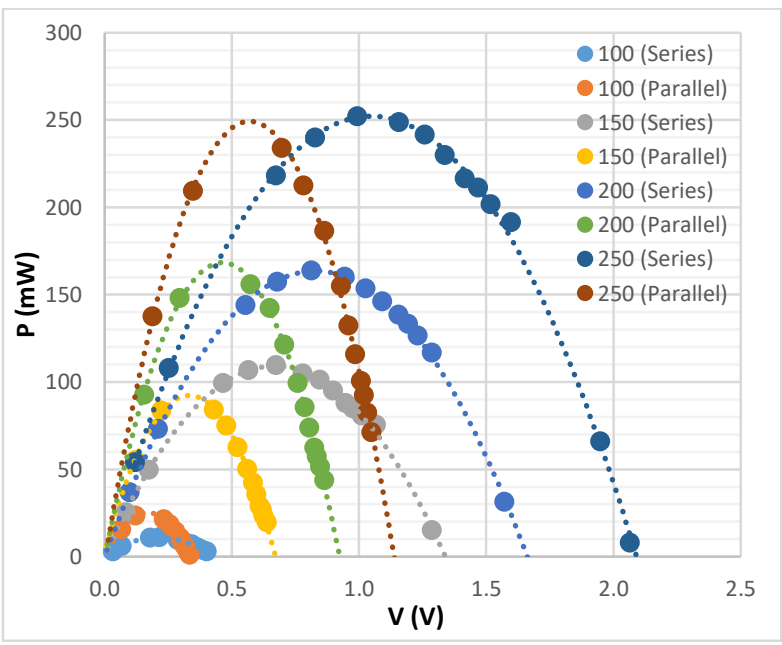

Fig. 13. Power output profile of series and parallel TEG

After that, as shown in Figure 13 the output power increase until it reached the maximum power point of the system. The value of the highest power output of series and the parallel connection was slightly in small difference values with series was $252 \mathrm{~mW}$ while parallel with $250 \mathrm{~mW}$. The experimental results show the performance of the series TEG connection better than a parallel connection. However, parallel array more reliable than series because individual TEG as an independent component in the circuit. If one of the TEG fails, the parallel pathway allows electricity to flow through another way compare to a series that only had one pathway of current to flow. It has not affected the other TEG when if one of them failed in connection.

The maximum power output against temperature difference had shown in Figure 14. The curve shows that the larger the temperature difference between hot and cold of TEG, the higher the maximum power output produced. The average temperature difference of TEG 1 and TEG 2 for series connection was $23.55^{\circ} \mathrm{C}$ resulted in the highest output power, $252 \mathrm{~mW}$. The average temperature difference of series and parallel connection only different in small value that produced the maximum power output.

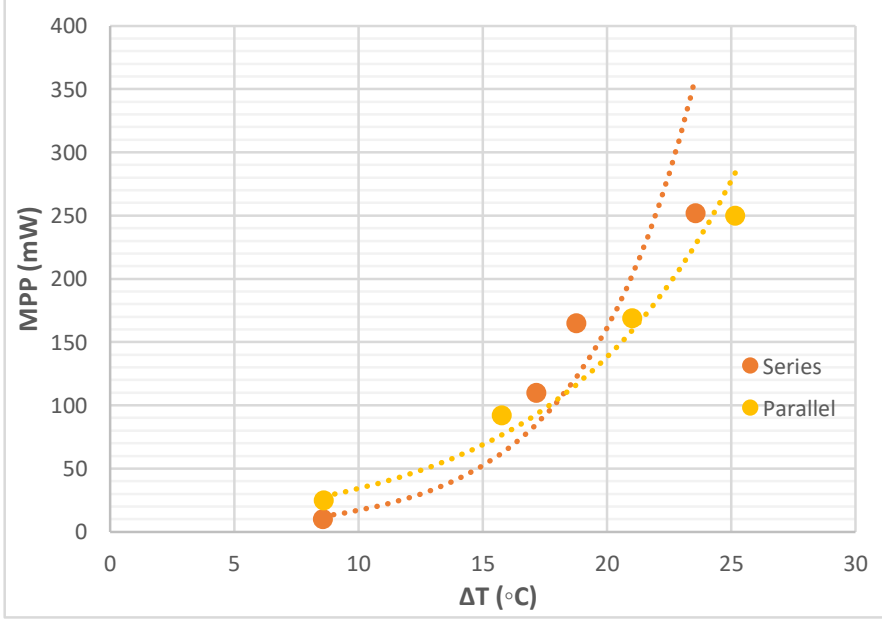

Fig. 12. Maximum power output at a various temperature different of series and parallel TEG 


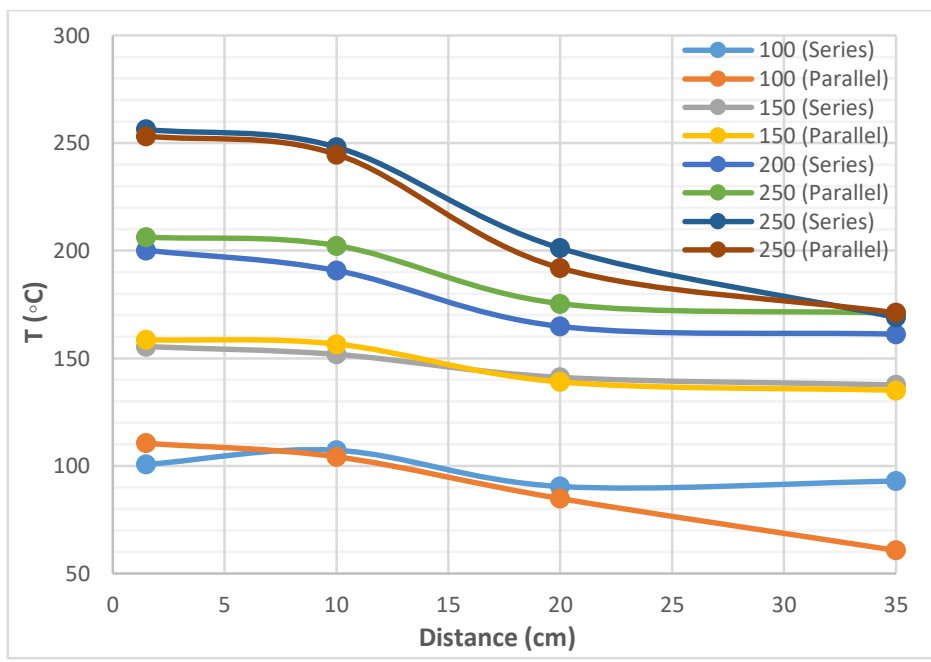

Fig. 13. Temperature along with the distance from heat source for series and parallel TEG

After that, the heat transmit along the heat exchanger was decrease as the distance far from the heat source as shown in Figure 15 for series and parallel TEG. For a parallel connection, the heat received with $253.2{ }^{\circ} \mathrm{C}$ and out with $171.2{ }^{\circ} \mathrm{C}$ at $250{ }^{\circ} \mathrm{C}$ waste heat source. The difference of the distance was $33.5 \mathrm{~cm}$ that resulting in the temperature out. Based on the result that recorded, the distance from the heat source resulting in the temperature produced at the outlet.

The time taken was recorded for series and parallel TEG to reach in steady-state had shown in Figure 16. It shows that the voltage took about 11 minutes to achieve the steady-state when no load applied in the system. The maximum time was 12 minutes for parallel TEG while the minimum time taken was 10 minutes took by series TEG to achieve the steady-state.

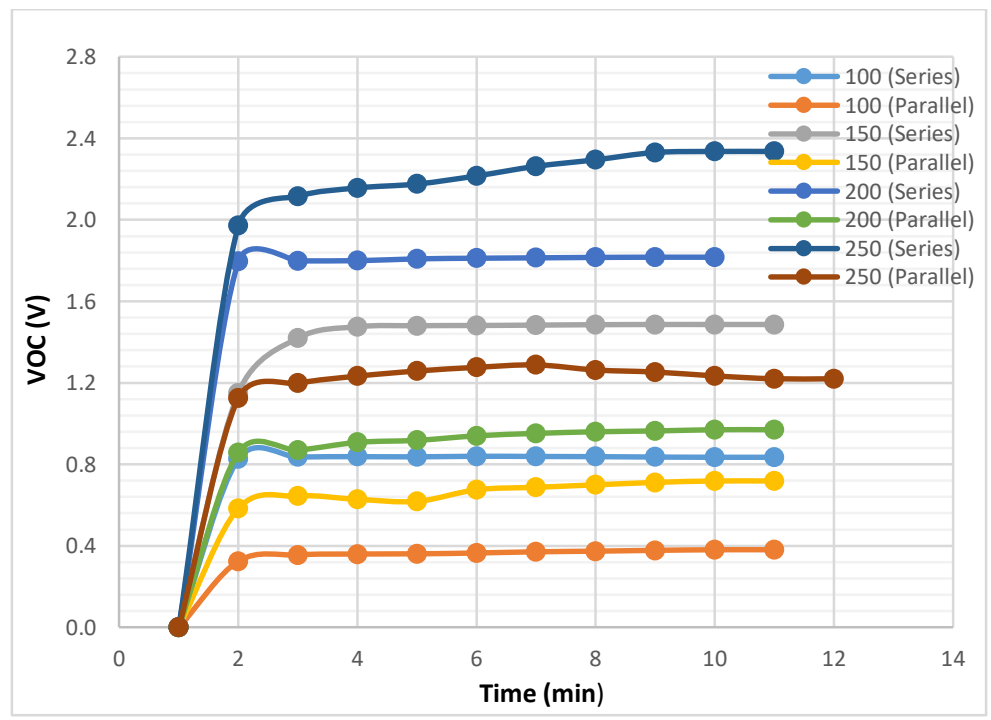

Fig. 14. Open circuit voltage against the time taken for series and parallel TEG 


\section{Conclusions \\ 4.1 Conclusion}

In conclusion, the power generation analysis by using a thermoelectric generator was conduct for a waste heat recovery system in the internal combustion engine of the car. The project had achieved the objectives outlines. From this project, it shows that multi-TEG in the system gave the best result of electrical characterization compare to individual TEG. From the experiment, TEG 1 performed well than TEG 2 because of the location position of them. From the experiment, the performance of TEG 1 able to obtain $183 \mathrm{~mW}$ of maximum power output at $250{ }^{\circ} \mathrm{C}$. The hot airflow always going up which resulted in the performance of TEG 1 . After that, the series connection proved that it achieved a higher voltage in the system that resulted in the highest maximum power output. The series TEG connection achieved the maximum power output, $252 \mathrm{~mW}$ at $250{ }^{\circ} \mathrm{C}$. However, the system of parallel array configuration more reliable than the series TEG. Moreover, the distance of point measured from the heat source also affected the temperature obtained. The heat along the system will decrease as the distance increase. The location of TEG was $20.75 \mathrm{~cm}$ from the inlet of the waste heat source. It affected the range of temperature differences that resulted in voltage and power generated. TEG was able to receive $80.1{ }^{\circ} \mathrm{C}$ of maximum hot temperature and $58.1^{\circ} \mathrm{C}$ of cold temperature that supplied from air cooling.

\subsection{Recommendations}

The recommendations towards the improvement of the further project to enhance better performance and result. The proposal as follows:

1. The temperature of the waste heat source needs to be enlarged in producing a large temperature difference of TEG.

2. Added more thermoelectric generator (TEG) to induce the maximum power of the system.

3. Develop a new reducer that attached to a heat exchanger to increase the airflow of the heat source.

4. Improve a new heat exchanger that attach with swirl nozzle at the inlet to increase the speed of the air.

5. Improve the test bench to allow the cooling airflow that gives better cooling modes for the TEG.

6. Use the proper and stable heat source to supply the waste heat source that eases to handle and control the parameter.

\section{Acknowledgement}

This research was funded by a grant from Universiti Teknologi MARA, Malaysia under Research Entity Initiative (REI) Grant (600-IRMI/DANA 5/3/REI (003/2018)).

\section{References}

[1] Milkov, N., T. Evtimov, and P. Plamen. "ADVANCED TECHNOLOGIES FOR WASTE HEAT RECOVERY IN INTERNAL COMBUSTION ENGINES." Machines. Technologies. Materials. 9, no. 8 (2015): 60-66.

[2] Chinguwa, Simon, Christopher Musora, and Tawanda Mushiri. "The design of portable automobile refrigerator powered by exhaust heat using thermoelectric." Procedia Manufacturing 21 (2018): 741-748. 10.1016/j.promfg.2018.02.179.

[3] Endo, Tsuneo, Shogo Kawajiri, Yoichi Kojima, Kazuya Takahashi, Tsuyoshi Baba, Shigeru Ibaraki, Tsutomu Takahashi, and M. Shinohara. "Study on maximizing exergy in automotive engines." SAE Transactions (2007): 347356.

10.4271/2007-01-0257. 
[4] H. M. Com, "How Hot Does an Exhaust Pipe / Muffler Get ?," 2019.

[5] Jouhara, Hussam, Navid Khordehgah, Sulaiman Almahmoud, Bertrand Delpech, Amisha Chauhan, and Savvas A. Tassou. "Waste heat recovery technologies and applications." Thermal Science and Engineering Progress 6 (2018): 268-289. 10.1016/j.tsep.2018.04.017.

[6] Soni, Lakshya, Pawan Kumar, and Rahul Goyal. "A Review on Waste Heat Recovery From Domestic Refrigerator." Imperial Journal Of Interdisciplinary Research (Ijir) 2.

[7] Abd Jalil, Mohd Izam, and Jahariah Sampe. "Experimental investigation of thermoelectric generator modules with different technique of cooling system." American Journal of Engineering and Applied Sciences 6, no. 1 (2013): 1-7. 10.3844/ajeassp.2013.1.7.

[8] Kumar, Ramesh C., Ankit Sonthalia, and Rahul Goel. "Experimental study on waste heat recovery from an IC engine using thermoelectric technology." Thermal science 15, no. 4 (2011): 1011-1022. 10.2298/TSCI100518053K.

[9] Love, N. D., James P. Szybist, and Charles S. Sluder. "Effect of heat exchanger material and fouling on thermoelectric exhaust heat recovery." Applied energy 89, no. 1 (2012): 322-328. 10.1016/j.apenergy.2011.07.042.

[10] AravindKaruppaiah.C, Ganesh.S, Dileepan.T, and Jayabharathi.S, "Fabrication and Analysis of Thermo ElectricGenerator For Power Generator," Int. J. Innov. Res. Sci. Eng. Technol., vol. 3, no. 1, pp. 1508-1513, 1970, [Online]. Available: http://www.rroij.com/open-access/pdfdownload.php?download=open-access/fabricationand-analysis-of-thermo-electricgenerator-for-power-generator.pdf\&aid=51432.

[11] R. Mathai Chandy Rakesh Rajeev, R. Lonappan Jose Thomas Lukose, and E. S. Assistant Professor, "Design and Analysis of Heat Exchanger for Automotive Exhaust based Thermoelectric Generator [TEG]," IJIRST-International J. Innov. Res. Sci. Technol., vol. 1, no. 11, pp. 291-298, 2015, [Online]. Available: www.ijirst.org.

[12] Liu, Xun, Y. D. Deng, Zhi Li, and C. Q. Su. "Performance analysis of a waste heat recovery thermoelectric generation system for automotive application." Energy conversion and management 90 (2015): 121-127.

10.1016/j.enconman.2014.11.015. 